\title{
Investigation of the Differential Thermodynamic Analysis of New Bifunctional Compositions Based on Navbahor Bentonites and Styrene-Acrylic Copolymers
}

\author{
Bakhtiyor Shukurullayevich Ganiyev, Muzaffar Samandarovich Sharipov* \\ Department of Chemistry, Faculty of Natural Science, Bukhara State University, Bukhara City, Uzbekistan \\ Email address: \\ b.ganiyev1990@gmail.com (B. S. Ganiyev), sharipovms1981@gmail.com (M. S. Sharipov) \\ ${ }^{*}$ Corresponding author
}

To cite this article:

Bakhtiyor Shukurullayevich Ganiyev, Muzaffar Samandarovich Sharipov. Investigation of the Differential Thermodynamic Analysis of New Bifunctional Compositions Based on Navbahor Bentonites and Styrene-Acrylic Copolymers. Chemical and Biomolecular Engineering.

Vol. 5, No. 1, 2020, pp. 35-40. doi: 10.11648/j.cbe.20200501.16

Received: December 14, 2019; Accepted: January 27, 2020; Published: February 11, 2020

\begin{abstract}
Compositions based on bentonite and acrylic copolymers were obtained. The dependence and improvement of the thermal characteristics of polymer compositions was also observed in the study of materials based on poly (styrene-coacrylamide) with bentonite clay of Navbakhor Deposit. The use of bentonites as fillers significantly increased the thermal properties of the resulting composites and to reduce their combustibility, which allows them to be used as slow-burning materials. That bentonite-filled composites are more thermally stable than unfilled copolymers. The use of various types of clays as polymer matrix modifiers allows us to solve a range of tasks from increasing the deformation-strength characteristics to obtaining materials of a given geometric shape, which leads to the creation of a whole assortment of new "intelligent" polymer composite materials. In addition to giving the polymer matrix improved strength characteristics, it is necessary that the composites retain their sorption properties, therefore, one of the types of fillers that are used are bentonites. This allows you to immediately unambiguously determine the nature of the processes in the substance, which is impossible to do only according to DTA or other thermodynamic methods. Research of polymer composite materials in work it was carried out on the derivatograph STD Q600 with a temperature range of $-25-500^{\circ} \mathrm{C}$ and the rate of temperature rise $-5^{\circ} \mathrm{C} / \mathrm{min}$. Differential scanning calorimetry is a universal, reliable and the most popular method of thermal analysis. He based on the measurement of the difference in heat flows coming from the subject the sample and the reference sample. Using differential scanning calorimetry (DSC) you can define a variety of variables that characterize properties of substances and materials and of interest as for the theory, and for practice. The speed of obtaining the results of the analysis, a large importance for solving research problems and quality control of raw materials and.
\end{abstract}

Keywords: Differential Thermodynamic Analysis, Differential Scanning Calorimetry, Bentonite clay, Filler, Acrylamide, Styrene, Copolymer, Composition, Monomer, Polymerization, Microstructure

\section{Introduction}

Hydrogels are polymer networks that take in and keep huge quantities of water. There are hydrophilic groups in the polymeric network, which become hydrated in aqueous media thus forming hydrogel structure. Because the term "network" is implied, cross-links must be present for the prevention of the dissolution of the polymer chains before use. Hydrogels may also be explored by the rheological manner. The solutions of water soluble polymers in low or intermediate concentrations where no considerable entanglement of chains occurs, normally exhibit 'newtonian' behavior.

Today, acrylic copolymers are used in various industries. They are used as drug delivery systems, fluids, contact lenses, prostheses, etc. [1-3]. The main properties of hydrogels that determine their practical use are a high degree of swelling and good physical and mechanical properties. However, in practice, a high degree of swelling leads to a significant deterioration in mechanical properties, such as 
strength and elasticity. In addition, cross-linked polymers, with high water absorption in the swollen state, lose their shape, which is unacceptable in the manufacture of products. All this is a significant disadvantage for materials based on acrylic water-absorbing copolymers.

There are various ways to solve this problem. One of these methods is the creation of mineral-containing polymer compositions. As inorganic fillers, most often, use different types of clay, carbon or glass fillers [4].

Polymerically modified clays are among the most promising organically modified clays because of their easily tuned surface properties using a variety of functional polymers. They have been widely used in many industrial fields, e.g., as catalysts, adsorbents, and fillers in preparing polymer-clay nanocomposites, etc. In general, polymerically modified clays could be obtained from absorption of organics, surface chemical grafting, or ion exchange with surfactants $[5,15,16]$. The properties of these polymerically modified clays are affected by the polymers used as well as the preparation methods, and in most cases their applications are limited by their properties [12-14].

For the polymerically modified clays prepared by physical absorption, their application fields are limited because of the weak force between polymer and clay surface. The method adapting the high-cost chemical grafting process to prepare the polymerically modified clays is most often appeared in the scientific research. Ion exchange of the sodium ions in the gallery of the clays with the polymeric quaternary ammonium ions is a most favorable method used in industries because of its lower cost.

In this study, copolimeric poly(styrene-co-acrylamide) modified clays (of the Navbakhor deposite) have been prepared through cation exchange of the lithium and sodium ions in the clay with the poly(styrene-co-acrylamide). One of the objectives of this study, is to find the relationships between the swelling property of these modified clays and the compositions of the polymers used; the other objective is to investigate the thermal stability of these modified clays (of the Navbakhor deposite) for the applications in nanocomposites by melting process.

And, this work presents the results of studying the effect of the concentration of bentonite filler in the preparation of waterabsorbing composite materials based on bentonite of the Navbakhor deposit (Uzbekistan), as well as acrylamide and styrene monomers with subsequent copolymerization of a colloidal suspension in a concrete matrix medium [22-25, 27].

\subsection{Physical Properties Crosslinked Gels}

Increased interest in physically cross-linked hydrogels in current era is due to the absence of cross-linkers used for synthesis. Following are the different methods to synthesize physically cross-linked hydrogels.

Polyacrylic acid and polymethacrylic acid make complexes with polyethylene glycol. These complexes have hydrogen bonding between the oxygen of the polyethylene glycol and the carboxylic group of polyacrylic acid/polymethacrylic acid [7]. Hydrogen bonding is found not only between polymethacrylic acid and polyethylene glycol, but also in poly (methacrylic acid-g-ethylene glycol) $[8,9]$. Hydrogen bonds are formed only if the protonation of carboxylic acid groups occurs which shows $\mathrm{pH}$ dependent swelling of the gels.

\subsection{Chemical Properties of Crosslinked Gels}

Chemically cross-linked hydrogels may be produced by free radical polymerization of polymerizable group derivatized hydrophilic polymers, besides free radical polymerization of vinyl monomers mixtures. To synthesize gels via this route, natural, synthetic and semi-synthetic hydrophilic polymers were applied. Using enzymes as catalyst, methacrylic groups have been introduced into the mono and disaccharides, which may be used for the hydrogel synthesis $[10,11]$. Moreover, by Ultra Violet polymerization, the hydrogel synthesis may be done, the planned structures may be synthesized and photo-reversible systems are also possible, which means that after exposing to Ultra Violet light, preformed hydrogels degrade and so a drug is released [21].

\subsection{Thermal Properties of Crosslinked Gels}

The use of bentonites as fillers can significantly improve the thermal properties of the resulting materials and reduce their combustibility [17-19], which allows them to be used as difficult-to-burn materials.

In work [20] thermal researches of composites on the basis of polyetherimide and sodium bentonite. It is shown that the temperature thermal decomposition of the polymer composition by TGA (differential thermodynamic analysis) method increased from $514.2^{\circ} \mathrm{C}$ for polymer without filler to $551.2^{\circ} \mathrm{C}$ for compositions containing bentonite $20 \mathrm{wt} . \%$. The DSC (differential scanning calorimetry) method was demonstrated glass transition temperature increased by $174^{\circ} \mathrm{C}$ to $210^{\circ} \mathrm{C}$ for composition with absence of bentonite and with content filler 20 wt.\% respectively.

\section{Materials and Research Methods}

For the synthesis of acrylic copolymers the following are used starting material:

1. Styrene;

2. Acrylamide;

3. Hydroxide;

4. N,N' - methylene bisacrylamide;

5. Tetramethylethylenediamine;

6. Ammonium persulfate (PSA)

Styrene should be purified from the inhibitor. For this distillation is used at $+38^{-}+43^{\circ} \mathrm{C}$ and a pressure of 8-12 $\mathrm{mmHg}$. art. water jet pump.

$\mathrm{N}, \mathrm{N}^{\prime}$ - methylene bisacrylamide is purified using recrystallization of ethyl alcohol. Hot saturated at $40^{\circ} \mathrm{C}$ a solution of $1 \mathrm{~g}$ of $\mathrm{N}, \mathrm{N}^{\prime}$ - methylene bisacrylamide is dissolved in $5 \mathrm{ml}$ of ethyl alcohol and filtered on a funnel for hot filtering. Precipitate white flake crystals are dried by 
vacuum drying or in thermostat. The dried crystals are stored either in a bux or in a desiccator. Since the purity of PSA has an impact on the physico-mechanical and sorption properties will also require recrystallization of the PSA.

Bentonites were used as fillers. Bentonite was provided by the Navbakhor Deposit of the Republic of Uzbekistan.

Derivatography is a complex research method chemical and physico-chemical processes occurring in a substance in conditions of programmed temperature change. Based on combination of differential thermodynamic analysis (DTA) with one or several physical or physico-chemical methods, for example, with thermogravimetry, thermomechanical analysis, mass- spectrometry and emanation thermodynamic analysis. In everything cases along with transformations in a substance occurring with thermal for example, a change in the mass of the sample is recorded. This allows you to immediately unambiguously determine the nature of the processes in the substance, which is impossible to do only according to DTA or other thermodynamic methods. Research of polymer composite materials in work it was carried out on the derivatograph STD Q600 with a temperature range of $-25-500{ }^{\circ} \mathrm{C}$ and the rate of temperature rise $-5^{\circ} \mathrm{C} / \mathrm{min}$. Differential scanning calorimetry is a universal, reliable and the most popular method of thermal analysis. He based on the measurement of the difference in heat flows coming from the subject the sample and the reference sample. Using differential scanning calorimetry
(DSC) you can define a variety of variables that characterize properties of substances and materials and of interest as for the theory, and for practice. The speed of obtaining the results of the analysis, a large importance for solving research problems and quality control of raw materials and

Fifty five products, ease of handling determine its increasing role in the the study of substances and materials. In the course of our work we used differential scanning calorimeter (DSC) DSC 8500. The sample was kept at a temperature of $-100^{\circ} \mathrm{C}$ within 7 minutes. The temperature was then raised from -100 to $250^{\circ} \mathrm{C}$ in $5^{\circ} \mathrm{C}$ increments per minute.

\section{Results and Discussions}

Table 1, Figures 1-4 show the results of thermogravimetric studies of bentonite-containing polymer composites of various compositions.

Figure 2 shows the DTA curves of new polymer acrylic compositions filled with Na-bentonite with a mass fraction of $5 \%$, in the figure 1 - DTA for unfilled acrylic copolymer, on figure 3 - DTA curves of an acrylic polymer composition containing $10 \mathrm{wt} . \%$ Filler - sodium bentonite.

Dependences of the mass loss of polymer mineralcontaining composites containing lithium and sodium forms of bentonite from heating temperatures are presented in table 1 .

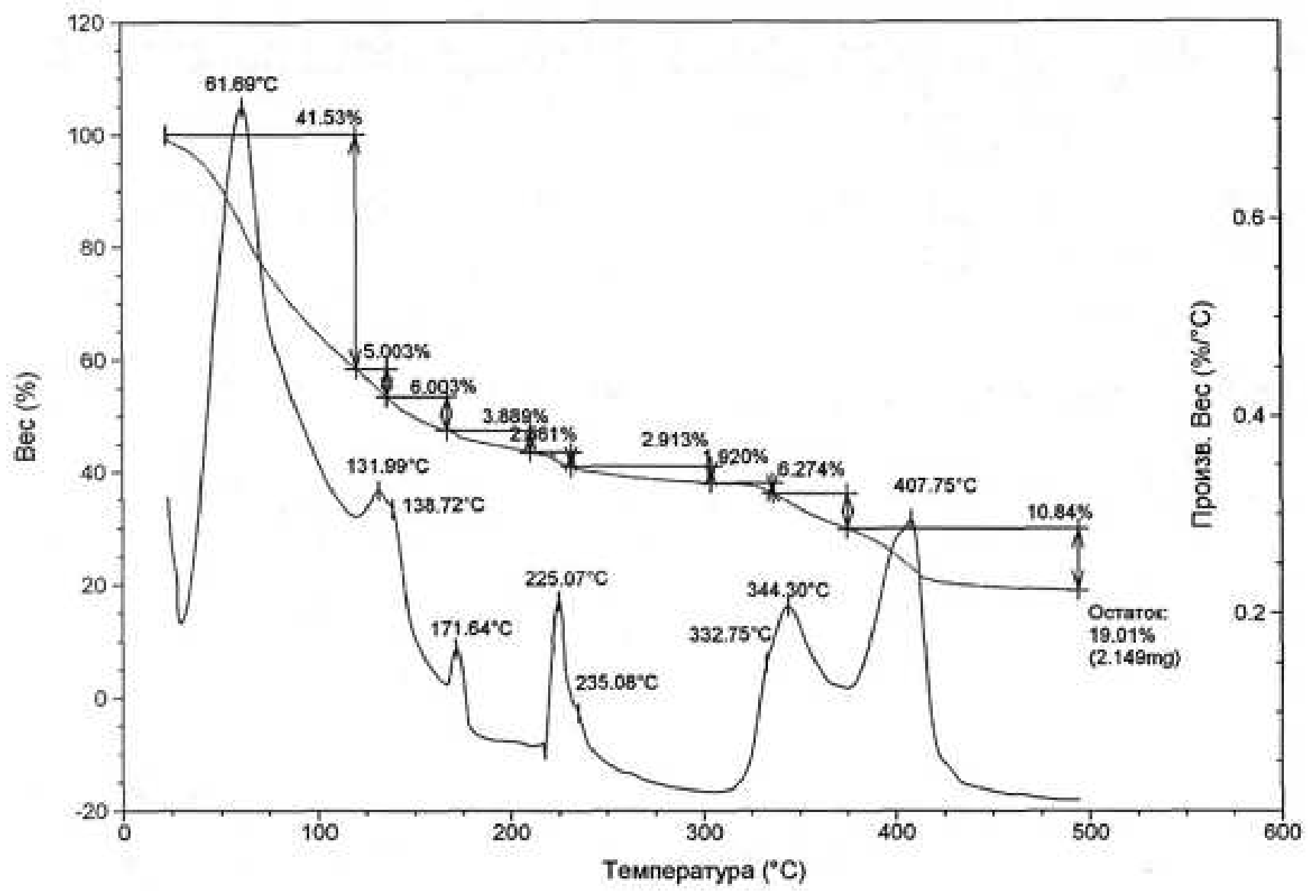

Figure 1. DTA data for acrylic copolymer. 


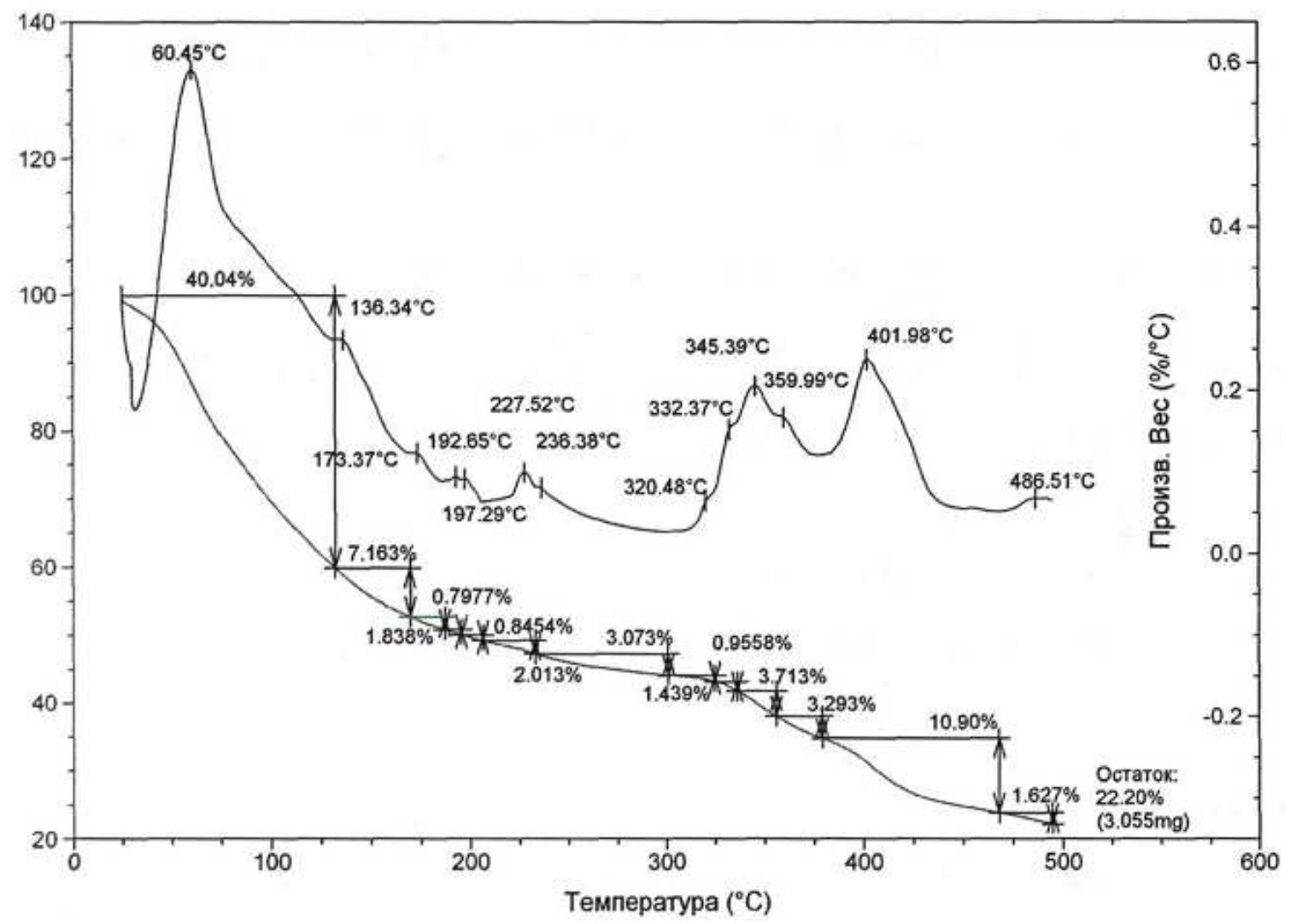

Figure 2. DTA curves for an acrylic composition with the concentration of Na-bentonite 5 wt.\%.

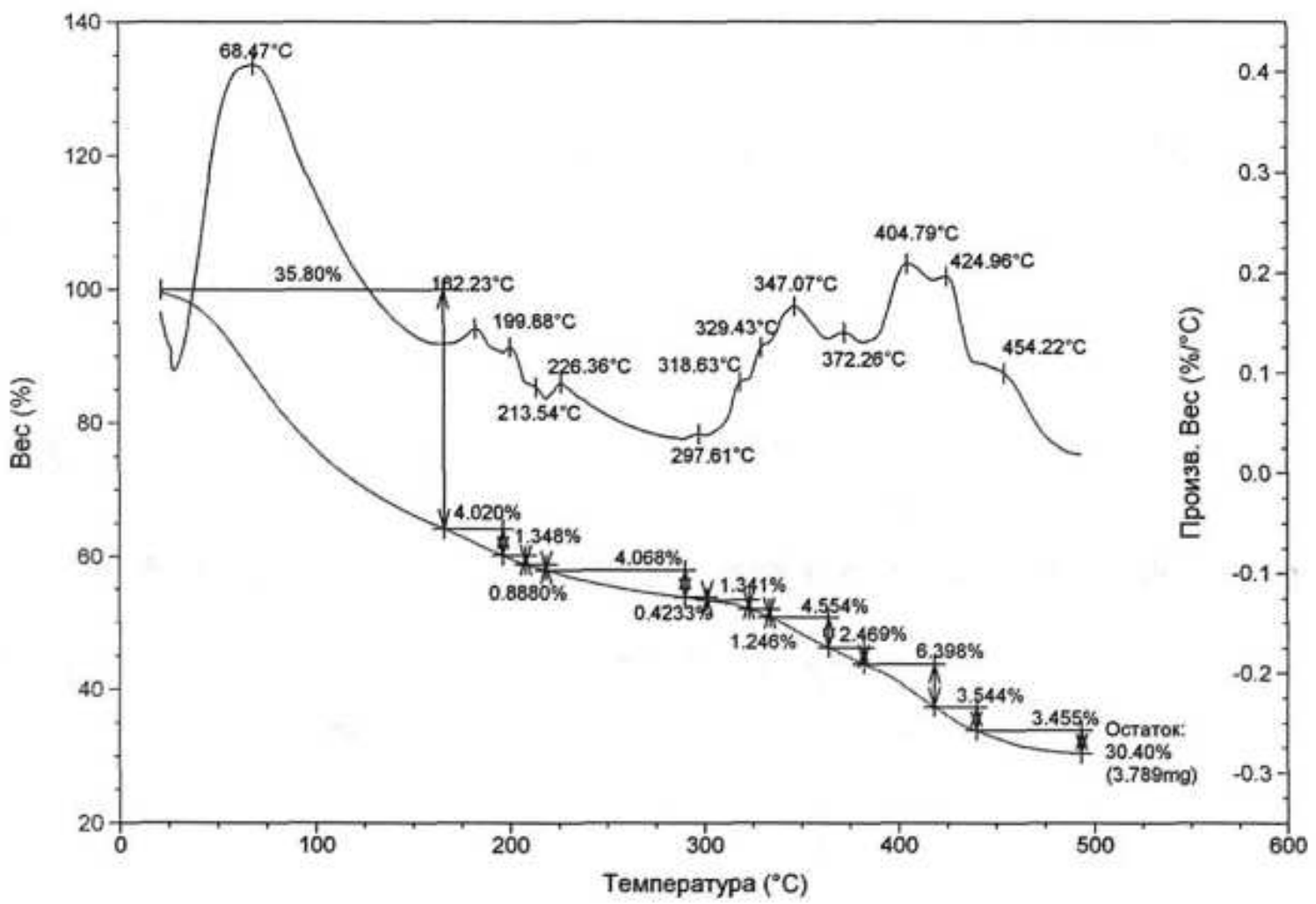

Figure 3. DTA curves for acrylic composition with the concentration of Na-bentonite $10 \mathrm{wt} . \%$.

As can be seen from table 1, Li-bentonite is more thermally stable than Na-bentonite. This can be explained by the influence of Li ions, which are part of Li-bentonite. 
Table 1. Dependence of mass loss on temperature for filled and unfilled acrylic compositions.

\begin{tabular}{|c|c|c|c|c|c|c|}
\hline \multirow{3}{*}{$\begin{array}{l}\text { A loss } \\
\text { masses, \% }\end{array}$} & \multicolumn{6}{|c|}{ Temperature, ${ }^{\circ} \mathrm{C}$} \\
\hline & \multicolumn{3}{|c|}{ Na-bentonite } & \multicolumn{3}{|c|}{ Li-bentonite } \\
\hline & $0 \%$ & $5 \%$ & $10 \%$ & $0 \%$ & $5 \%$ & $10 \%$ \\
\hline $10 \%$ & 60 & 73 & 85 & 60 & 65 & 65 \\
\hline $25 \%$ & 70 & 85 & 105 & 75 & 90 & 130 \\
\hline $50 \%$ & 130 & 180 & 340 & 150 & 190 & 350 \\
\hline
\end{tabular}

With an increase in the proportion of both lithium and sodium forms of bentonite as part of the polymer composition, the temperature of loss of $50 \%$ mass the polymer sample of the composite increases by 2-2.5 times.
Bentonite has high thermal stability, and its the layered structure has a barrier effect to prevent evaporation of small molecules produced during thermal effects, and limits the decomposition of the matrix itself [26].

Intense transition observed at $65^{\circ} \mathrm{C}$, see figure 4 , probably associated with the glazing of acrylic acid. His shift in higher temperatures $\left(75^{\circ} \mathrm{C}\right)$ after filling the polymer can be associated with the beginning of evaporation of water loosely associated with the filler, that confirmed by DSC data for bentonite (wide peak on the curve heat flow in the range from 50 to $\left.120^{\circ} \mathrm{C}\right)$.

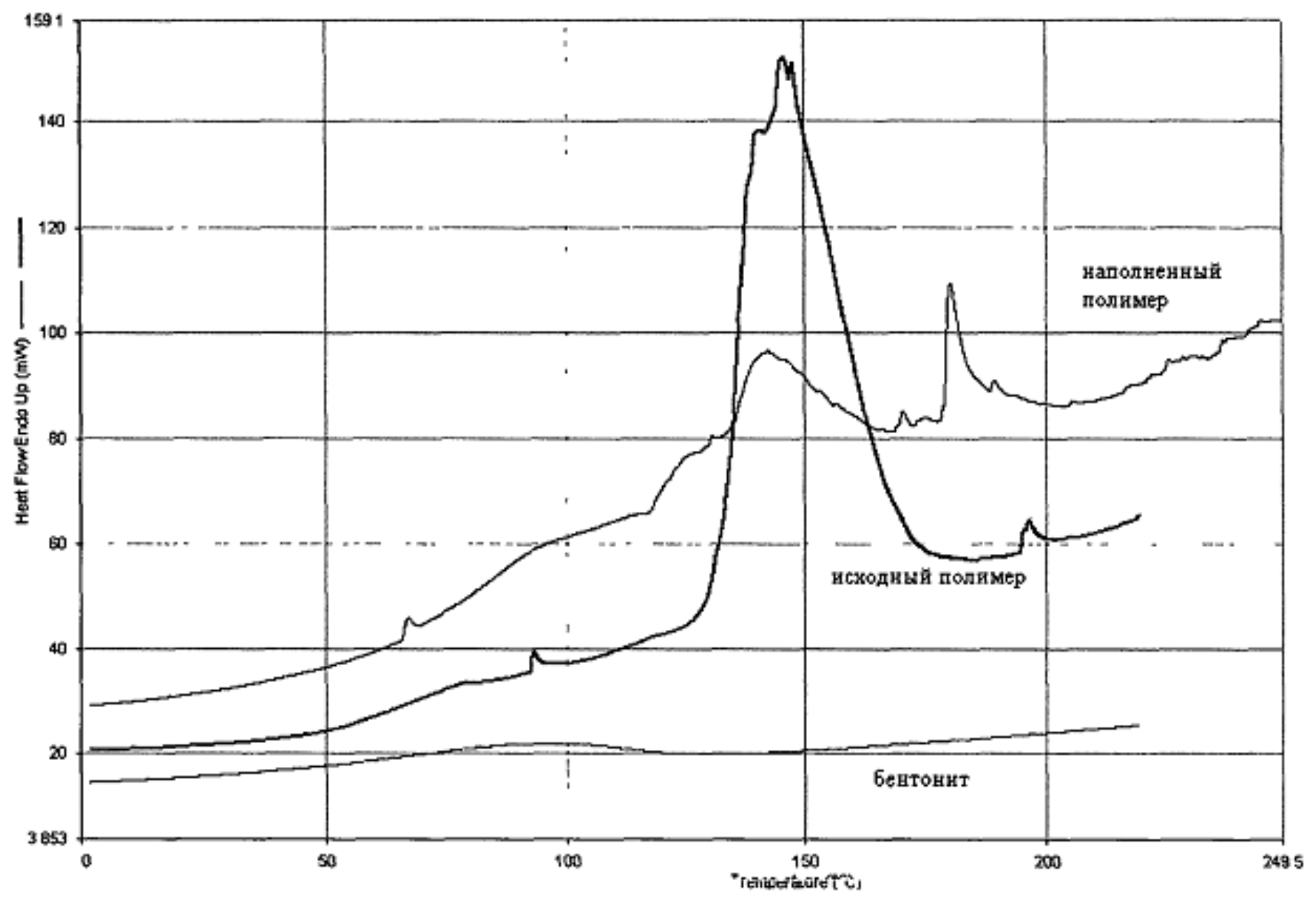

Figure 4. DSC Thermograms for acrylic compositions with concentration of sodium bentonite-15 wt.\%.

\section{Conclusion}

From table 1 it is seen that the composites filled with bentonite are more thermally stable than unfilled copolymers. Thermal stability increases on average 1.5 times with an increase in the proportion of $\mathrm{Na}$ - bentonite from $0 \%$ to $10 \mathrm{wt} . \%$ with a mass loss of $10 \%$, for Li-bentonite with the same mass loss - the heating temperature remains practically unchanged.

Peaks at 180 and $195^{\circ} \mathrm{C}$ in the original and filled polymer respectively, may also relate to the phase transition of acrylamide, the peak intensity of the filled polymer is more than 5 times exceeds the peak intensity of the unfilled polymer. Thus, we can say that the introduction of bentonite leads to slightly more lasting water retention in the system, although it does redistribution of the intensity of the stages of its evaporation by temperature.

The resulting composite materials are slow-burning and are recommended for the assembly of elements of fireproof structures.

\section{Acknowledgements}

The authors are grateful to Professor of the National University of Uzbekistan Mukhammadiyev Mukhtorjon Ganievich, and the staff of the Institute of General and Inorganic Chemistry of the Academy of Sciences of Uzbekistan for their practical assistance in the preparation of the article. 


\section{References}

[1] Noyan, H.; Onal, M.; Sarikaya, Y. Clays Clay Miner 2006, 54, 375.

[2] Mathur A. M., Moorjani S. K., Scranton A. B. Methods for Synthesis of Hydrogels Networks: A Review // Journal of Macromolecular Science. Part. C: Chem. Phys. - 1996. - V. 36, № 2. - P. 405-430.

[3] Evsikova O. V., Starodubtsev S. G., Khokhlov A. R. Synthesis, swelling and adsorption properties of composites based on polyacrylamide gel and sodium bentonite // high molecular compounds. - 2002. - T. 44, № 5. - C. 802-808.

[4] Zhany F., Fang S., Song Q. Using of bentonites for sewage treatment. // Ind. Water Treat. - 2003. - Vol. 6. - P. 11-13.

[5] Erim, F. B.; Alemdar, I.; Fresenius, J. Anal Chem 1998, 361, 455.

[6] Uspenskaya M. V., Soloviev B. C. Creation of materials based on bentonite and acrylate copolymers // Materials of the allRussian forum of students, postgraduates and young scientists "Science and innovations in technical universities", 2007 October. - P. 109.

[7] Eagland, D. et al, 1994. Complexation between polyoxyethylene and polymethacrylic acid-the importance of the molar mass of polyethylene. Eur. Polym. J. 30, 767-773.

[8] Bell, C. L., Peppas, N. A., 1996. Modulation of drug permeation through interpolymer complexed hydrogels for drug delivery applications. J. Control. Rel. 39, 201-207.

[9] Mathur, A. M. et al, 1998. Equilibrium swelling of poly(methacrylic acid-g-ethylene glycol) hydrogels. J. Control. Rel. 54, 177-184.

[10] Patil, N. S. et al, 1996. Macroporous poly(sucrose acrylate) hydrogels for controlled release of macromolecules. Biomaterials 17, 2343-2350.

[11] Patil, N. S. et al, 1997. Sucrose diacrylate: a unique chemically and biologically degradable crosslinker for polymeric hydrogels. J. Polym. Sci. Part A Polym. Chem. 35, 2221-2229.

[12] Piletsky, S. A.; Piletska, E. V.; Chen, B. N.; Karim, K.; Weston, D.; Barrett, G.; Lowe, P.; Turner, A. P. F. Anal Chem $2000,72,4381$.

[13] Anbarasan, R.; Vasudevan, T.; Gopalan, A. Eur Polym J 2000, $36,1725$.

[14] Tsubokawa, N. Prog Polym Sci (UK) 1992, 17, 417.

[15] Rheinlander, T.; Klumpp, E.; Schwuger, M. J. J Dispersion Sci Technol 1998, 19, 379.
[16] Xu, S. H.; Boyd, S. A. Langmuir 1995, 11, 2508.

[17] J. T. Yoon, W. H. Jo, M. S. Lee, M. B. Ko / Effects of comonomers and shear on the melt intercalation of styrenics/clay nanocomposites // Polymer. - 2001. - Vol. 42. P. 329-336.

[18] E. P. Giannelis, R. Krishnamoorti, E. Manias / PolymerSilicate Nanocomposites: Model Systemsfor Confined Polymers and Polymer Brushes // Advances in Polymer Science. - 1998. - Vol. 138. - P. 107-146.

[19] Jin Woo Lee, Yong Taik Lim, O Ok Park / Thermal characteristics of organoclay and their effects upon the formation of polypropylene/organoclay nanocomposites // Polymer Bulletin. - 2000. - Vol. 4 5. - P. 191-198

[20] Jun-Chao Huang, Zi-kang Zhu, Jie Yin, Xue-feng Qian, YangYang Sun/ Poly(etherimide)/montmorillonite nanocomposites prepared by meltintercalation: morphology, solvent resistance properties and thermal properties// Polymer. - 2001. - Vol. 42. - P. 873-877.

[21] Andreopoulos, F. M. et al, 1998. Light-induced tailoring of PEG hydrogel properties. Biomaterials 19, 1343-1352.

[22] Ganiyev B. Sh., Sharipov M. S. To study the effect of temperature and time on the yield of styrene forming a sopolimer with acrylamide. Materials of the Republican scientific-practical conference "actual problems of Chemical Science and innovative technologies in its teaching". Tashkent 2016y. - P. 186-187.

[23] Ganiyev B. Sh., Sharipov M. S. Study of the properties of natural sorbents and their modified forms. Materials of the Republican scientific-practical conference "actual problems of Chemical Science and innovative technologies in its teaching". Tashkent 2016y. - P. 159-161.

[24] Ganyiev B. Sh., Sharipov M. S. Synthesis and Characterization of Poly(styrene-co-acrylamide) Polymers. Republican scientific and Practical Conference of young scientists Part II. Termiz, 2017 y. - P. 128.

[25] Ganiyev B. Sh., Sharipov M. S. Influence of initiator concentration on absorption properties polymer composite. IV All-Russian conference Chemistry and chemical technology: achievements and prospects. On November 27-28. Kemerovo. 2018. - P. 316.1.

[26] Kazuhisa Yano, Arimitsu Usuki, Akane Okada, Toshio Kurauchi, Osami Kamigaito, Synthesis and Properties dof Polyimide-Clay Hybrid // Journal of Polymer Science Part A: Polymer Chemistry. 1993, Volume 31, Issue 10, P. 2493-2498.

[27] Ganiyev B. Sh., Sharipov M. S., Gapurov U. U. Study of the rheological properties of thickener compositions based on bentonite and water soluble polyacrylates for textile printing. Problems of Bioorganic chemistry. IX Republican scientific and Practical Conference of young scientists Part I. Namangan. 2019 y. -P. 164. 